\title{
High Hydrostatic Pressure for Disinfection of Bone Grafts and Biomaterials: An Experimental Study
}

\author{
Hans Gollwitzer ${ }^{*}, 1$, Wolfram Mittelmeier ${ }^{2}$, Monika Brendle ${ }^{1}$, Patrick Weber ${ }^{1,3}$, Thomas Miethke ${ }^{4}$, \\ Gunther O. Hofmann ${ }^{5}$, Ludger Gerdesmeyer ${ }^{1}$, Johannes Schauwecker ${ }^{1}$ and Peter Diehl ${ }^{2}$
}

\author{
${ }^{1}$ Klinik und Poliklinik für Orthopädie und Unfallchirurgie, Technische Universität München, Ismaninger Strasse 22, \\ 81675 München, Germany \\ ${ }^{2}$ Orthopädische Klinik, Universität Rostock, Doberaner Str. 142, 18057 Rostock, Germany \\ ${ }^{3}$ Department of Orthopaedic Surgery, Großhadern Medical Center, Ludwig Maximilian University, Marchioninistr. 15, \\ 81377 München, Germany \\ ${ }^{4}$ Institut für Medizinische Mikrobiologie, Immunologie und Hygiene, Technische Universität München, Ismaninger \\ Strasse 22, 81675 München, Germany \\ ${ }^{5}$ Berufsgenossenschaftliche Kliniken "Bergmannstrost", Merseburger Str. 165, 06116 Halle (Saale), Germany
}

\begin{abstract}
Background: Autoclaving, heat, irradiation or chemical detergents are used to disinfect autografts, allografts and biomaterials for tissue reconstruction. These methods are often associated with deterioration of mechanical, physical, and biological properties of the bone grafts and synthetic implants. High hydrostatic pressure has been proposed as a novel method preserving biomechanical and biological properties of bone, tendon and cartilage. This is the first study to assess the inactivation of clinically relevant bacteria on biomaterials and human bone by high hydrostatic pressure.

Methods: Bacterial suspensions of Staphylococcus aureus, Pseudomonas aeruginosa and Enterococcus faecium, implants covered with infected blood, human bone infected in vitro, and biopsies of patients with chronic osteomyelitis were subjected to different protocols of high hydrostatic pressure up to $600 \mathrm{MPa}$. Bacterial survival after high hydrostatic pressure treatment was determined and compared with bacterial growth in untreated controls.

Results: $S$. aureus and $P$. aeruginosa in suspension were completely inactivated by high hydrostatic pressure (>5log levels), whereas E. faecium showed barotolerance up to $600 \mathrm{MPa}$. Blood and adherence to metal implants did not significantly alter inactivation of bacteria, and complete disinfection was achieved with barotolerant bacteria $(S$. aureus and $P$. aeruginosa). However, osteoarthritic bone demonstrated a non-homogeneous baroprotective effect, with single bone samples resistant to treatment resulting in unaltered bacterial growth, and complete disinfection of artificially infected bone specimens was achieved in $66 \%$ for $S$. aureus, $60 \%$ for $P$. aeruginosa and $0 \%$ for $E$. faecium. Human bone samples of patients with chronic osteomyelitis could be completely disinfected in 2 of 37 cases.

Conclusion: High hydrostatic pressure offers new perspectives for disinfection of sensitive biomaterials and bone grafts, and contamination by blood did not significantly affect bacterial inactivation rates. However, a significant baroprotective effect was demonstrated in bone. Effectiveness is currently limited to colonization and / or infection with barosensitive micro-organisms.
\end{abstract}

Keywords: High pressure, osteomyelitis, bacterial inactivation, tissue transplant, tissue graft.

\section{INTRODUCTION}

Regeneration and reconstruction of human organs and tissue defects is one of the central challenges in modern medicine. There is a wide variety of different approaches to fill bone and joint defects, including tissue engineering, allograft transplantation, reimplantation of extracorporally treated autografts, or implantation of synthetic biomaterials. A major drawback of all reconstruction modalities is infection, thus

*Address correspondence to this author at the Department for Adult Hip and Knee Reconstruction, Klinik für Orthopädie und Unfallchirurgie, Technische Universität München, Ismaninger Str., 22, D-81675 Munich, Germany; Tel: +49-89-4140-2271; Fax: +49-89-990-18319;

E-mail: gollwitzer@bone-and-joint.org requiring some kind of prophylaxis. Irradiation, autoclaving and chemical detergents are commonly used for disinfection of biomaterials and bone transplants, and might even allow reimplantation of infected or tumour-afflicted tissue after sterilisation. These conventional methods, however, severely alter biomechanical and biological properties of bone transplants [1-3]. Accordingly, there is an urgent clinical demand for alternative ways of treating contaminated human tissue and sterilization-sensitive biomaterials prior to implantation.

High hydrostatic pressure (HHP) as a means of food processing has been examined intensively for more than 100 years [4]. As most vegetative forms of micro-organisms are impaired by hydrostatic pressure in the range of 300-600 
MPa, non-thermal inactivation of bacteria, yeasts, and moulds present in food such as jams, fruit juices, and dressings is now well-established. Furthermore, HHP proved a relatively mild disinfection method protecting taste and appearance of treated comestibles [4].

Recently, Diehl and co-workers have shown HHP to be a promising approach in orthopaedic surgery as well. Inactivation of normal tissue and various tumour cells could be demonstrated [5-7], with pressure levels leaving biomechanical properties of human bone, articular cartilage or tendon grafts unchanged [8-10]. Furthermore, no immunhistochemical changes were detectable in HHP treated tendon tissue [8], and biological activity of extracellular bone matrix proteins also remained unaffected [11].

Until now, HHP has not been introduced in the medical field for the disinfection of human tissue or heat-, gas-, or radiation-sensitive biomaterials. In this regard, the objective of the study was to assess HHP inactivation of clinically relevant bacteria on biomaterials and in human bone tissue under physiological conditions. Furthermore, different treatment protocols for maximum bacterial inactivation rates were evaluated in clinically oriented models. The hypothesis was that HHP is capable to completely disinfect both bacterial suspensions, as well as metallic implants and infected bone specimens.

\section{MATERIALS AND METHODS}

\section{Preparation of Bacteria}

Reference strains of Enterococcus faecium (ATCC 6057), Staphylococcus aureus (ATCC 25923) and Pseudomonas aeruginosa (ATCC 27853) were used for the in vitro studies. A methicillin resistant strain of $S$. aureus (MRSA 27065 ) isolated from a deep arthroplasty infection was also subjected to HHP treatment. Bacteria were cultured to late logarithmic growth phase in trypticase soy broth (TSB) at 37 ${ }^{\circ} \mathrm{C}$ overnight before testing. Bacterial cells were then washed twice in phosphate buffered saline, resuspended in normal saline $(\mathrm{NaCl} 0.9 \%)$ and adjusted to $5 \times 10^{7} \mathrm{cfu} / \mathrm{ml}$ by densitometry with McFarland standard ( $\mathrm{cfu}=$ colony forming units).

\section{Hydrostatic Pressure Treatment}

HHP treatment was realised by a custom-made HHP device (RECORD Maschinenbau GmbH, Königssee, Germany) with temperature control. Pliable sample vials of a volume of $15 \mathrm{ml}$ were completely filled with incubation fluid and vacuum sealed within a plastic foil to prevent implosion and leakage during pressure application. Pressurisation and decompression was performed with an average rate of 10 $\mathrm{MPa} / \mathrm{s}$ and water used as transmission fluid. Pressure and temperature were continuously measured and regulated automatically during the HHP plateau time.

\section{HHP Treatment of Bacterial Suspensions}

Susceptibilities of suspended E. faecium ATCC 6057, S. aureus ATCC 25923 and P. aeruginosa ATCC 27853 toward HHP were determined ( $\mathrm{n}=5$ for each group). In brief, bacterial suspensions of $10^{5} \mathrm{cfu} / \mathrm{ml}$ were prepared as described above and subjected to $600 \mathrm{MPa}$ at $20^{\circ} \mathrm{C}$ for $10 \mathrm{~min}$.
Untreated suspensions served as a control $(n=5)$. Hereafter, serial aliquots of both test and control suspensions diluted with normal saline were plated on blood agar plates and incubated at $37^{\circ} \mathrm{C}$. The number of cfu was quantified after 48 hours.

\section{HHP Disinfection of Human Osteomyelitic Bone}

Bone biopsies from patients with chronic osteomyelitis or infected total joint arthroplasties that were gained during operative debridement were subjected to HHP treatment for proof-of-principle. Informed consent was obtained from all patients, and only bone specimens that had to be excised for surgical debridement were taken for the present investigation. To simulate a worst-case scenario, bacteria within the infected bone samples were enriched and incubated to stationary growth phase prior to pressure application. A total of 71 bone biopsies were obtained for HHP treatment in 21 operations (12 patients, mean age 67 years [range 25 - 78]).

Specimens were immediately placed in sterile Ringer's solution in the operation theatre, transported to the laboratory on ice, transferred to TSB and incubated for 5 days at 37 ${ }^{\circ} \mathrm{C}$. Thereafter, bacterial outgrowth was verified and the infecting bacteria were determined by standard microbiological techniques. Bone specimens with negative bacterial culture were discarded. Samples were exposed to HHP treatment under aseptic conditions as described above (for treatment parameters see Table 1). At least one specimen of each operation served as a control and was not exposed to HHP. After pressure application, bone samples were transferred to sterile TSB and incubated for 5 days at $37{ }^{\circ} \mathrm{C}$ for assessment of bacterial survival.

Table 1. Bone Specimens of Patients with Osteomyelitis were Obtained, Incubated and Subjected to High Hydrostatic Pressure $\left(\mathrm{HHP}, 2^{\circ} \mathrm{C}, 30 \mathrm{~min}\right)$

\begin{tabular}{|c|c|c|}
\hline $\begin{array}{c}\text { Bacteria } \\
\text { Pre-Treatment }\end{array}$ & $\begin{array}{c}\text { HHP } \\
{[\text { MPa] }}\end{array}$ & $\begin{array}{c}\text { Samples After } \\
\text { HHP (Sterile/Total) }\end{array}$ \\
\hline \hline S. aureus & 450 & $0 / 7$ \\
\hline S. aureus & 600 & $1 / 17$ \\
\hline S. aureus \& CNS & 600 & $0 / 3$ \\
\hline CNS & 600 & $0 / 6$ \\
\hline Escherichia coli & 300 & $0 / 2$ \\
\hline Escherichia coli & 600 & $1 / 2$ \\
\hline
\end{tabular}

Table 1 shows the isolated micro-organisms and results after pressure treatment. $\mathrm{CNS}=$ coagulase negative staphylococci.

\section{HHP Treatment of Contaminated Biomaterial Surfaces}

To determine the effectiveness of HHP for disinfection of contaminated biomaterials, a standard testing protocol modified after a national guideline was developed [12]. In brief, carefully cleaned and sterilized screws of stainless steel (DIN 84, standard size $6 \times 20 \mathrm{~mm}$ ) were used as substrates. Inoculum concentrations were adjusted to $10^{6} \mathrm{cfu} / \mathrm{ml}$ in defibrinized blood of adult sheep. Sterile screws were completely immersed in the infected blood for at least 1 minute and finally dried in Petri dishes at $37^{\circ} \mathrm{C}$ for 24 hours. 
Prior to treatment with HHP, the infected screws were placed in pliable plastic vials completely filled with $15 \mathrm{ml}$ of TSB. The specimens were kept on ice before and after HHP treatment. Sample size was $\mathrm{n}=5$ for each experiment displayed in Table 2, and untreated screws served as a control.

After pressure application, all screws were treated with ultrasound $(55 \mathrm{kHz}$, Sonorex RK255H, Bandelin electronic, Berlin, Germany) for $7 \mathrm{~min}$ to remove adherent microorganisms, and serial dilutions of the bacterial suspensions were plated on blood agar plates. Finally, cfu were quantified after 48 hours of incubation at $37^{\circ} \mathrm{C}$.

\section{HHP Treatment of Artificially Infected Bone Specimen}

Human femoral heads of three patients receiving a total hip arthroplasty due to aseptic osteoarthritis were used for the in vitro bone infection model after informed consent was obtained. Average age was 69 years (44-71). The femoral heads were explanted and stored at $-20{ }^{\circ} \mathrm{C}$ until examination. After defrosting at room temperature, bone cylinders with a diameter of $11 \mathrm{~mm}$ and a length of $10 \mathrm{~mm}$ were prepared from the specimens with a hollow drill under aseptic conditions.

Bacterial suspensions with an inoculum concentration of $10^{5} \mathrm{cfu} / \mathrm{ml}$ were prepared in TSB as described above. Bone cylinders were incubated in $5 \mathrm{ml}$ of the bacterial suspension for 24 hours at $37^{\circ} \mathrm{C}$, transferred to sterile plastic vials filled with $15 \mathrm{ml}$ of TSB, and subjected to HHP treatment. Bone specimens of the different test groups were either infected with $S$. aureus ATCC 25923, E. faecium ATCC 6057 or $P$. aeruginosa ATCC 27853. Thereafter, pressure levels of 600 $\mathrm{MPa}$ were applied for $10 \mathrm{~min}, 30 \mathrm{~min}$ or six five-minute intervals at $37^{\circ} \mathrm{C}(\mathrm{n}=5$ for each series).

After HHP treatment, the bone samples were transferred to $10 \mathrm{ml}$ of TSB and incubated for 24 hours to determine bacterial growth $\left(37{ }^{\circ} \mathrm{C}\right)$. Serial aliquots were taken, plated on blood agar plates and quantified after incubation for another 24 hours. If no bacterial growth was detected, incubation of the bone samples was prolonged until a total incubation period of 5 days was reached to assure disinfection $\left(37^{\circ} \mathrm{C}\right)$.

\section{Statistical Analysis}

Means and standard deviations were determined whenever applicable. Statistical analysis was performed with
Mann-Whitney-Test with $\mathrm{P}<0.05$ considered significant.

\section{RESULTS}

\section{HHP Treatment of Bacterial Suspensions}

Bacterial growth of all suspended strains was significantly reduced after HHP treatment compared to the untreated control $(P<0.05)$. Both $S$. aureus ATCC 25923 and $P$. aeruginosa ATCC 27853 were completely inactivated by $10 \mathrm{~min}$ of $600 \mathrm{MPa}$, corresponding to a reduction of bacterial growth of at least 5 logarithmic levels. E. faecium ATCC 6057 on the other hand proved high barotolerance, and growth was only reduced to $62 \pm 4 \%$ of the control group.

\section{HHP Disinfection of Human Osteomyelitic Bone}

Results of HHP treatment of osteomyelitic bone are displayed in Table 1. Microbiological work-up revealed monoinfections in all cases. Nine samples did not show bacterial growth after enrichment and were discarded prior to HHP treatment. Finally, 62 specimens from 12 different patients were evaluated. Twenty-five samples served as a control, 2 were treated with $300 \mathrm{MPa}, 7$ were treated with $450 \mathrm{MPa}$ and 28 samples were treated with $600 \mathrm{MPa}\left(30 \mathrm{~min} ; 20^{\circ} \mathrm{C}\right)$. Disinfection was achieved in 2 of the 37 treated specimens. All control samples showed positive bacterial growth.

\section{HHP Treatment of Contaminated Biomaterial Surfaces}

Bacterial growth on standard screws after HHP is displayed in Fig. (1). Growth of E. faecium ATCC 6057 was not inhibited significantly by HHP treatment up to $600 \mathrm{MPa}$ $(P>0.05)$. S. aureus ATCC 25923 and MRSA 27065 on the other hand showed a significant reduction of growth with increasing pressure levels $(P<0.01)$. After applying 400 $\mathrm{MPa}$, only single colony forming units of both strains survived, and complete disinfection was achieved with 600 $\mathrm{MPa}$ (Fig. 1).

After modification of the treatment protocol, bacterial inactivation by HHP was even improved. As demonstrated for $S$. aureus ATCC 25923, both reduction of the treatment temperature in the pressure device to $4{ }^{\circ} \mathrm{C}$ as well as lengthening of the pressure plateau to $30 \mathrm{~min}$ significantly increased bacterial inactivation at $300 \mathrm{MPa}(P<0.05)$. Complete inhibition of staphylococcal growth was already ob-

Table 2. Treatment Parameters for the Application of HHP to Disinfect Stainless Steel Screws

\begin{tabular}{|c|c|c|c|c|}
\hline Exp. & Bacterial Strain & Pressure Levels [MPa] & Temperature [ $\left.{ }^{\circ} \mathbf{C}\right]$ & Pressure Time [Min.] \\
\hline \hline 1 & S. aureus ATCC 25923 & $0,200,300,400$ & 4 & 10 \\
\hline 2 & S. aureus ATCC 25923 & $0,200,300,400$ & 4 & 30 \\
\hline 3 & S. aureus ATCC 25923 & $0,200,300,400$ & 20 & 30 \\
\hline 4 & S. aureus ATCC 25923 & $0,200,300,400$ & 20 & 10 \\
\hline 5 & MRSA 27065 & $0,200,300,400$ & 20 & 10 \\
\hline 6 & E. faecium ATCC 6057 & $0,200,300,400$ & 20 & 30 \\
\hline 7 & S. aureus ATCC 25923 & 0,200 & 0,200 & 6 \\
\hline 8 & S. aureus ATCC 25923 & 5 & 20 \\
\hline
\end{tabular}




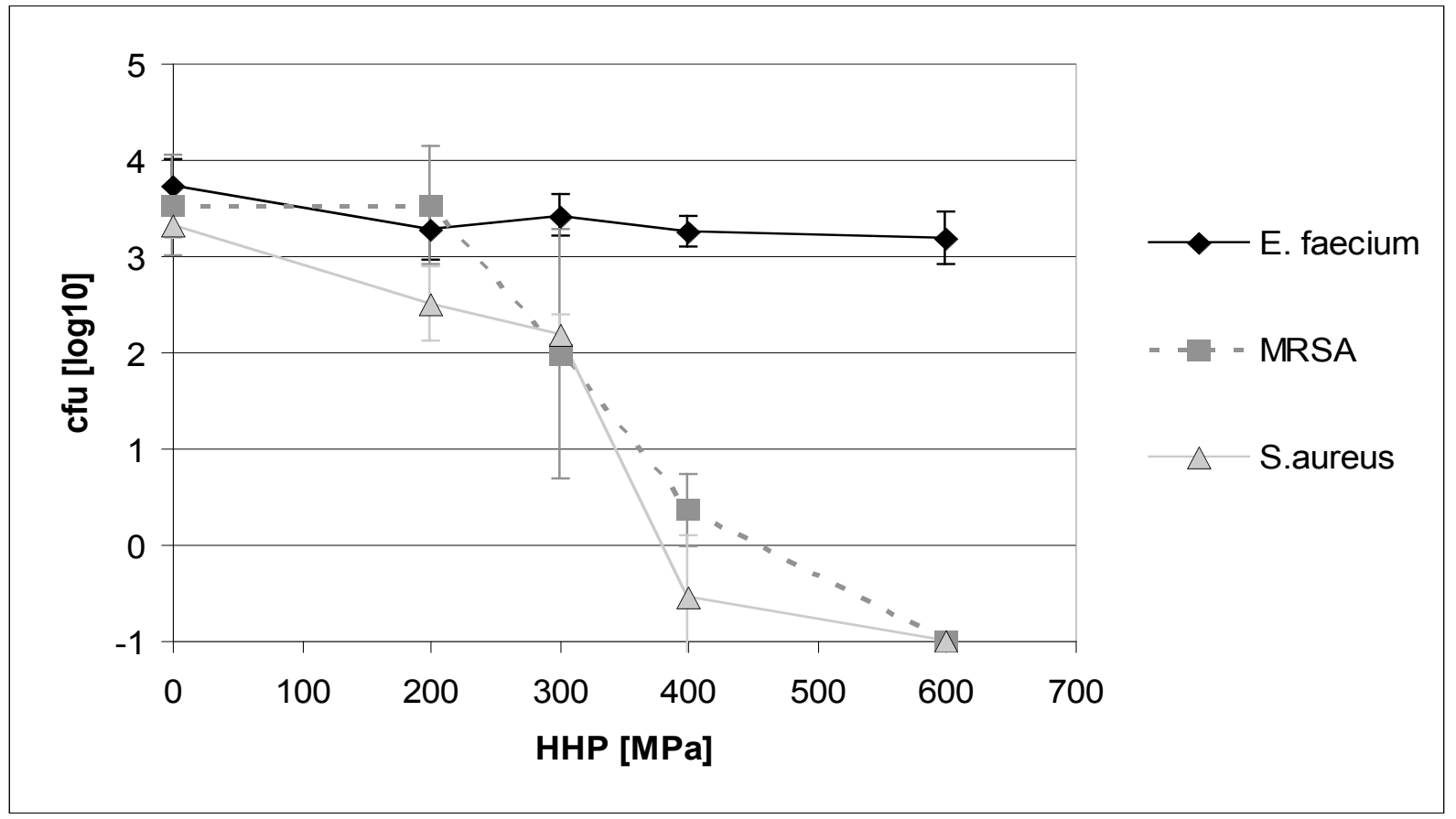

Fig. (1). Inactivation of different bacterial strains on stainless steel screws by high hydrostatic pressure $\left(10\right.$ min, $\left.20{ }^{\circ} \mathrm{C}\right)$. Colony forming units (cfu) after treatment are shown in logarithmic levels.

tained with $300 \mathrm{MPa}$ at $4^{\circ} \mathrm{C}$ or after $30 \mathrm{~min}$ of HHP, whereas $400 \mathrm{MPa}$ and more were necessary for disinfection with a 10 min pressure plateau at $20{ }^{\circ} \mathrm{C}$ (Fig. 2).

\section{HHP Treatment of Artificially Infected Bone Specimen}

Antibacterial action of HHP in bone was evaluated after treatment with $600 \mathrm{MPa}$. Interestingly, some bone samples demonstrated unaffected bacterial growth after HHP ("non- responder"), whereas others were disinfected by HHP application ("responder"). Thus, results showed a high standard deviation.

Good antibacterial effectiveness of HHP could be demonstrated for $S$. aureus and $P$. aeruginosa, and the majority of bone specimens infected with these micro-organisms were completely disinfected (Fig. 3). Disinfection was achieved in $66 \%$ of bone samples infected with $S$. aureus, and in $60 \%$

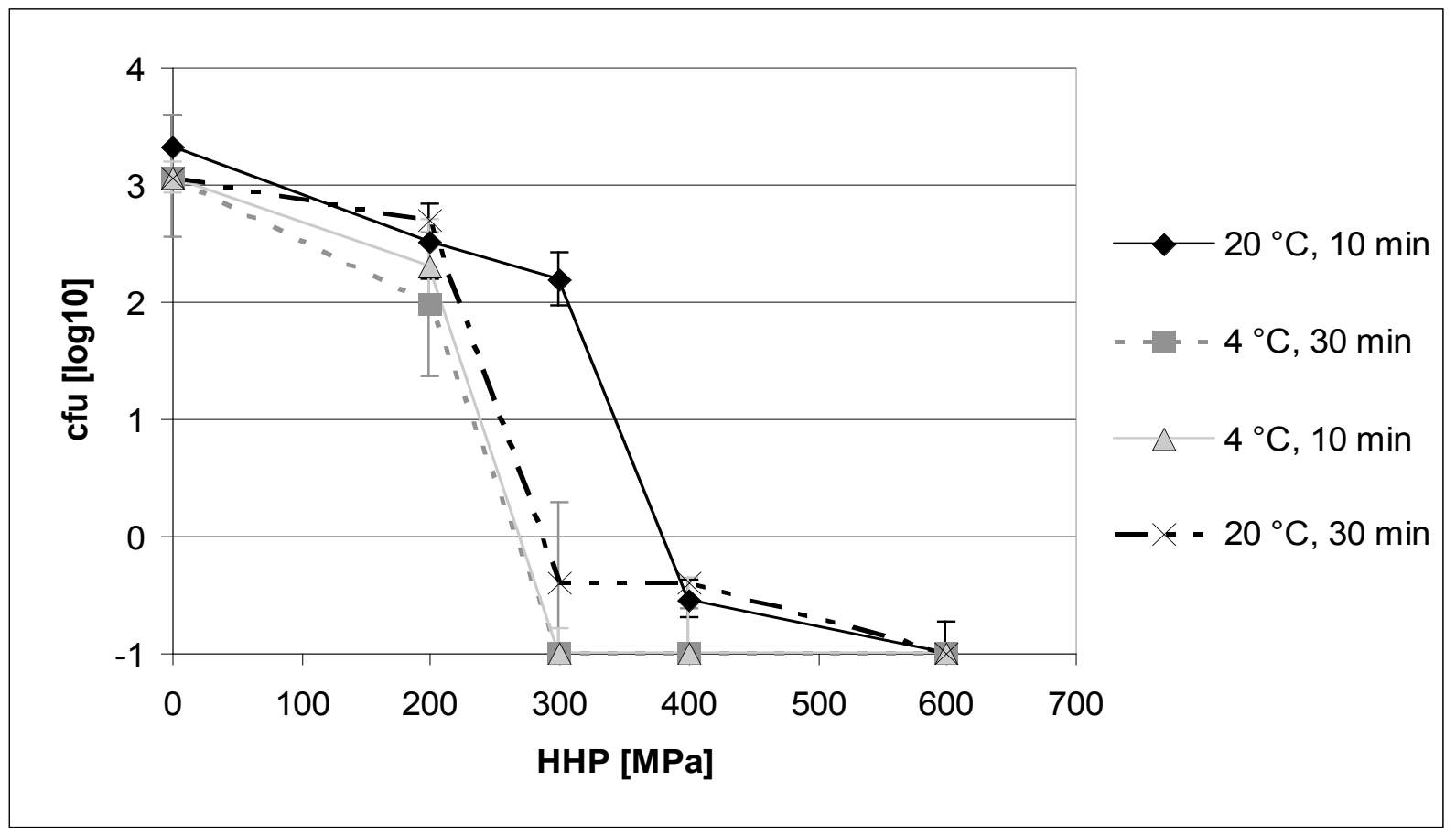

Fig. (2). Growth inhibition of Staphylococcus aureus ATCC 25923 on stainless steel screws by high hydrostatic pressure with different treatment protocols. Colony forming units (cfu) after treatment are shown in logarithmic levels. 


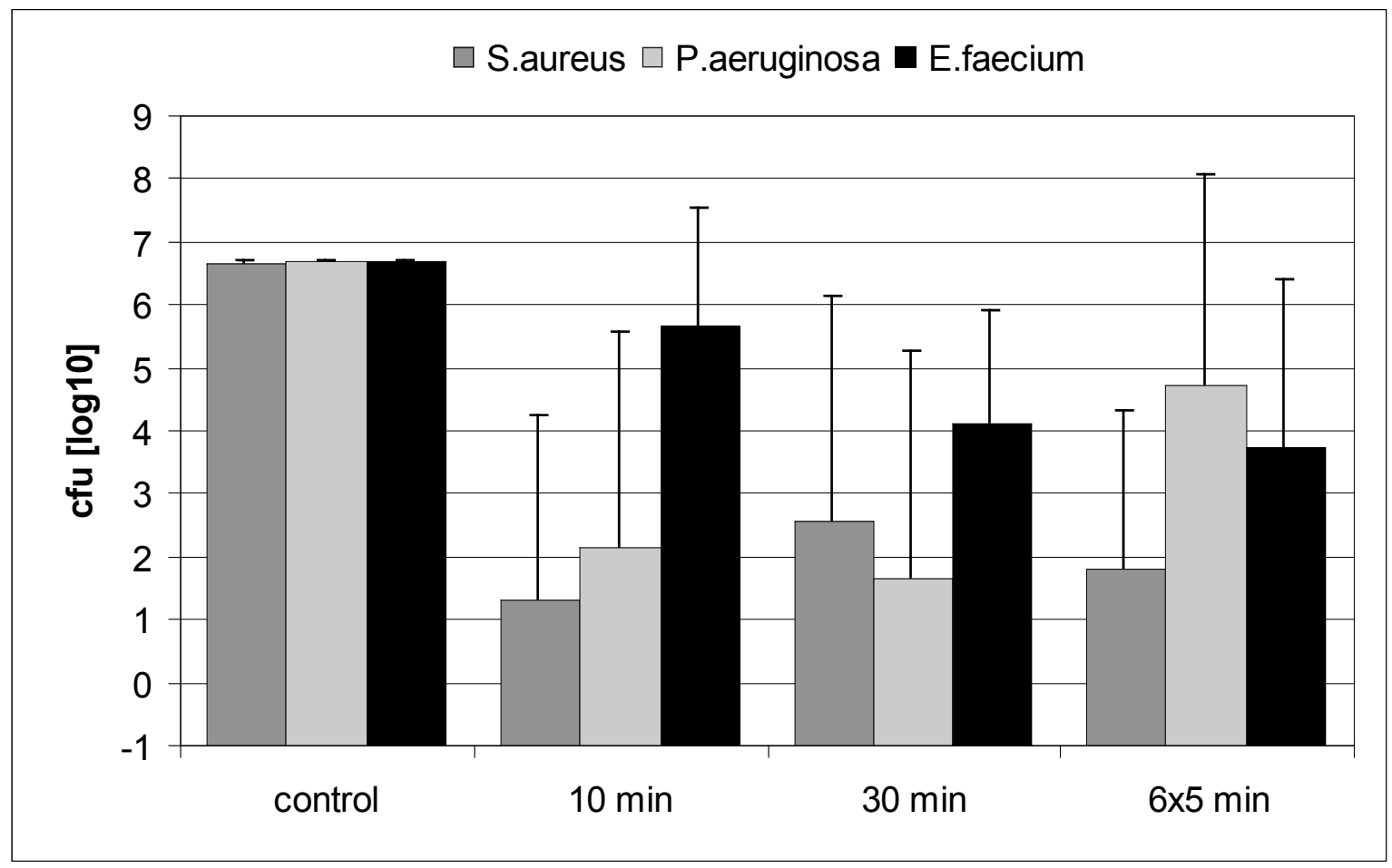

Fig. (3). Bacterial growth of $S$. aureus ATCC 25923, E. faecium ATCC 6057 and P. aeruginosa ATCC 27853 after high hydrostatic pressure treatment of infected bone specimens with different protocols $\left(600 \mathrm{MPa}, 37^{\circ} \mathrm{C}\right)$. Values are displayed in logarithmic levels of colony forming units (cfu) after HHP application.

of samples infected with $P$. aeruginosa. However, HHP failed to significantly reduce bacterial growth in single samples. Consequently, standard variations were high and no significant differences were observed between HHP treated and untreated control group $(P>0.05)$. E. faecium again demonstrated high barotolerance. No sample was completely disinfected though viable bacteria were also reduced in some specimens. There was no significant difference in antibacterial effectiveness between the different treatment protocols $(P>0.05)$, and neither prolongation of treatment nor iterating pressure application did overcome the baroprotective effect originated by the surrounding bone.

\section{DISCUSSION}

Disinfection of infected autografts, allografts and biomaterials for therapy of bone defects is often associated with deterioration of mechanical, physical and biological properties. HHP technology is suggested as a novel approach, now being in preclinical testing with the aim to disinfect grafts and implants, and to inactivate both micro-organisms and tumour cells in resected tissue segments. By leaving the biomechanical and biological properties of bone, cartilage and tendons intact, HHP could improve quality of allografts and might even allow reimplantation of bone segments of patients with osteomyelitis or tumours after extracorporal HHP disinfection.

\section{Antibacterial Effects of HHP}

In the pressure range of biotechnological interest, hydrostatic pressure has in general no effect on covalent bonds. Therefore, natural compounds such as flavours, aromas, and dyes are not destroyed by HHP at room temperature. Nucleic acids also proved pressure resistant because their secondary structure is mainly stabilised by hydrogen bonds that are almost pressure insensitive. However, transcription and translation were reported to be regularly influenced by HHP [13]. The main targets of HHP seem to be membrane systems leading to an increased permeability of membranes and cell walls [14]. Shigehisa et al. reported an increased permeabilisation of bacterial cell walls by HHP followed by an elevated discharge of cytoplasmatic RNA [15], and membrane leakage after HHP treatment leading to increased intracellular staining was shown by Benito et al. [16]. Changes in membrane fluidity similar to those observed with thermal treatment and inactivation have been reported as well [17], and may explain the interactions of pressure and temperature. After adjustment of treatment parameters, successful inactivation of bacteria, moulds, yeasts, viruses and even bacterial spores has been described [18].

Results of our present study with suspended and surfaceadherent bacteria confirmed the significant variations in pressure susceptibility reported in the literature even within bacterial species [16, 19], and results obtained for specific strains should therefore not be widely generalised. Both barosensitive and barotolerant strains had been selected. $P$. aeruginosa and $S$. aureus could be completely inactivated in suspension, whereas growth of E. faecium was only reduced by $38 \%$ even at HHP as high as $600 \mathrm{MPa}$. These differences in barotolerance were also reproduced with bacteria adhering to implants and bone. Although the molecular mechanisms of barotolerance have not been completely discovered, it is well renown that gram positive strains - like E. faecium - are generally more barotolerant than gram negative strains [23, 24]. Furthermore, single strains have shown barotolerance up 
to pressure levels of more than $1000 \mathrm{MPa}$ [29]. In our study, the investigated strain of E. faecium that has been reported to be very heat resistant [12] has also demonstrated extraordinary pressure tolerance.

\section{Influence of Media, Additives and Treatment Parameter on Bacterial Inactivation by HHP}

Various investigations demonstrated that additives within the treatment media may have significant influence on bacterial barotolerance $[20,21]$. In order to apply HHP for disinfection of bone and biomaterials, it is inevitable to proof uninhibited antibacterial effectiveness also in the presence of organic residua like proteins and blood. Thus, microbiological assays were performed with bacteria embedded in blood on screws, and with infected bone.

Our results provide evidence that blood does not alter bacterial inactivation by HHP compared to suspensions in TSB. In addition to these findings, we were able to demonstrate that both decreasing treatment temperature and prolonging pressure application allowed complete inactivation of $S$. aureus on contaminated screws already at decreased pressure levels (Fig. 2). As expected, susceptibility of $E$. faecium was not altered by the different treatment protocols up to $600 \mathrm{MPa}$ of HHP (Fig. 1). Our results are thus in accordance with previously published data, demonstrating temperature levels above $50^{\circ} \mathrm{C}$ and below $5^{\circ} \mathrm{C}$ to increase bacterial inactivation by HHP $[4,19,22]$. Ludwig et al. explained the important influence of treatment temperature on the antibacterial effectiveness of HHP by changes in the membrane composition rendering bacteria more or less sensitive towards HHP [23]. Influence of temperature on inactivation again varies significantly between the different bacterial strains [24].

\section{HHP Disinfection of Bone}

Femoral heads from patients with aseptic osteoarthritis, which are commonly used as allogeneic bone grafts, were infected in vitro and subjected to HHP to assess the influence of heterogeneous bone with areas of necrosis and sclerosis on the antibacterial effectiveness of HHP. Interestingly, the heterogeneous constitution of the bone specimens was reflected by an enormous variation of bacterial inactivation by HHP. Various bone specimens could be completely disinfected, whereas others proved resistant to treatment with unaffected bacterial growth (Fig. 3). Histological and biochemical parameters of the different bone samples were not correlated to the inactivation rates in the present work and should be addressed in future studies.

Apart from the in vitro experiments, we were able to demonstrate that HHP is also capable to reduce bacterial growth in human osteomyelitic bone ex vivo. However, complete disinfection of the human bone specimens was only achieved in 2 out of 37 samples. "Worst case scenarios" have been simulated in the test assay with enrichment of the infecting micro-organisms prior to HHP application. After the enrichment period, a very high bacterial load was reached with most bacteria in stationary phase being less susceptible to HHP [25]. Thus, pressurisation can be expected to be more effective if applied directly to the microbiota of the collected specimens.
Our findings clearly indicate that bone can protect embedded bacteria from HHP, since $S$. aureus and $P$. aeruginosa were reproducibly inactivated in suspension and in blood, but not in bone. An explanation for the baroprotective effect of bone might be a lack of water molecules, which are known to enhance the pressure effect, and water was less present in the examined dry bone samples compared to bacterial suspensions. The influence of different bone constituents on HHP inactivation of micro-organisms might also play an important role and has been studied for other reasons. An increased fat content is typical for degenerative bone diseases. However, Gervilla et al. did not observe any baroprotective effect of the fat content within the treatment medium on pressurised bacteria [26]. Different results have been reported for sugars like sucrose [27] and divalent cations. Especially $\mathrm{Ca}^{2+}$ demonstrated a dose-dependent baroprotective effect [28].

We anticipate that HHP can be established as a disinfection method to reduce viability of barotolerant microorganisms on heat-, gas- and radiation-sensitive biomaterials. Although bacteria were effectively eradicated in single infected specimens, HHP failed to safely disinfect both infected bone samples as well as infected metal implants. Antibacterial efficacy can be increased with elevated pressure levels and adjusted treatment temperature. Indications might however be limited to mono-infections with barotolerant bacteria. Contamination of screws with infected blood had no influence on bacterial inactivation by HHP, compared to the same bacteria in suspension. Disinfection of bone allografts, however, was significantly limited by a baroprotective effect of bone tissue, and the underlying mechanisms of these specimens resistant to therapy have to be addressed in further studies.

\section{ACKNOWLEDGEMENTS}

This study was supported by a grant from the Bayerische Forschungsstiftung (Bavarian Research Association for Tissue Engineering and Rapid Prototyping TE 3 "FORTEPRO") of the Bavarian Ministry of Science, Culture and Education. Funding had no involvement in, or control over, the running of the study, the decision to publish, or the content of this paper. None of the authors has any financial or professional affiliations with the funding source. The authors did not receive any payments or benefits by any other research fund, foundation, educational institution or other non-profit organisation or from a commercial or industrial party.

We acknowledge the technical support of Dr. Gerrit Blümelhuber from the Department of Energy and Environmental Technical Food Industry of the Technical University of Munich, Germany.

\section{REFERENCES}

[1] Sugimoto M, Takahashi S, Toguchida J, Kotoura Y, Shibamoto Y, Yamamuro T. Changes in bone after high-dose irradiation. Biomechanics and histomorphology. J Bone Joint Surg Br 1991; 73-B(3): 492-7.

[2] Hamer AJ, Strachan JR, Black MM, Ibbotson CJ, Stockley I, Elson RA. Biochemical properties of cortical allograft bone using a new method of bone strength measurement. A comparison of fresh, fresh-frozen and irradiated bone. J Bone Joint Surg Br 1996; 78$\mathrm{B}(3)$ : 363-8. 
[3] Borchers RE, Gibson LJ, Burchardt H, Hayes WC. Effects of selected thermal variables on the mechanical properties of trabecular bone. Biomaterials 1995; 16(7): 545-51.

[4] Cheftel JC. High-pressure, microbial inactivation and food preservation. Food Sci Technol Int 1995; 1: 75-90.

[5] Diehl P, Reuning U, Gollwitzer H, et al. Effect of extracorporal high hydrostatic pressure on tumor cell adherence and viability. Oncol Rep 2004; 12(2): 369-73.

[6] Schauwecker J, Wirthmann L, Schmitt M, et al. Effect of extracorporeal high hydrostatic pressure on cellular outgrowth from tumorafflicted bone. Anticancer Res 2006; 26(1A): 85-9.

[7] Naal FD, Mengele K, Schauwecker J, et al. High hydrostatic pressure-induced cell death in human chondrocytes and chondrosarcoma cells. Anticancer Res 2005; 25(3B): 1977-82.

[8] Diehl P, Steinhauser E, Gollwitzer H, et al. Biomechanical and immunohistochemical analysis of high hydrostatic pressure-treated Achilles tendons. J Orthop Sci 2006; 11(4): 380-5.

[9] Diehl P, Naal FD, Schauwecker J, et al. Biomechanical properties of articular cartilage after high hydrostatic pressure treatment. Biomed Technik (Berl) 2006; 51(1): 8-14.

[10] Steinhauser E, Hadaller M, Diehl P, et al. Biomechanical investigation of the effect of high hydrostatic pressure treatment on mechanical properties of human bone. J Biomed Mater Res B Appl Biomater 2006; 76(1): 130-5.

[11] Diehl P, Schmitt M, Schauwecker J, et al. Effect of high hydrostatic pressure on biological properties of extracellular bone matrix proteins. Int J Mol Med 2005; 16(2): 285-9.

[12] Robert Koch-Institut des Bundesgesundheitsamtes. Richtlinie des Bundesgesundheitsamtes zur Prüfung von thermischen Desinfektionsverfahren in Reinigungsautomaten. Bundesgesundheitsblatt 1980; 23: 364-7.

[13] Hoover DG. Pressure effects on biological-systems. Food Technol 1993; 47(6): 150-5.

[14] Perrier-Cornet JM, Hayert M, Gervais P. Yeast cell mortality related to a high-pressure shift: occurrence of cell membrane permeabilization. J Appl Microbiol 1999; 87(1): 1-7.

[15] Shigehisa T, Ohmori T, Saito A, Taji S, Hayashi R. Effects of high hydrostatic pressure on characteristics of pork slurries and inactivation of microorganisms associated with meat and meat products. Int J Food Microbiol 1991; 12(2-3): 207-15.

[16] Benito A, Ventoura G, Casadei M, Robinson T, Mackey B. Variation in resistance of natural isolates of Escherichia coli $\mathrm{O} 157$ to high hydrostatic pressure, mild heat, and other stresses. Appl Environ Microbiol 1999; 65(4): 1564-9.
[17] Tsuchido T, Miyake K, Hayashi M, Tamura K. Similar characteristics of bacterial death caused by high temperature and high pressure: Involvement of membrane fluidity. In: Hayashi M, Balncy C, Eds. High pressure bioscience and biotechnology. Elsevier Science, 1996; pp. 185-8.

[18] Cléry-Barraud C, Gaubert A, Masson P, Vidal D. Combined effects of high hydrostatic pressure and temperature for inactivation of Bacillus anthracis spores. Appl Environ Microbiol 2004; 70(1): 635-7.

[19] Alpas H, Kalchayanand N, Bozoglu F, Sikes A, Dunne CP, Ray B. Variation in resistance to hydrostatic pressure among strains of food-borne pathogens. Appl Environ Microbiol 1999; 65(9): 424851.

[20] Hauben KJ, Wuytack EY, Soontjens CCF, Michiels CW. Highpressure transient sensitization of Escherichia coli to lysozyme and nisin by disruption of outer-membrane permeability. J Food Prot 1996; 59: 350-5

[21] Kalchayanand N, Sikes A, Dunne CP, Ray B. Factors influencing death and injury of foodborne pathogens by hydrostatic pressurepasteurization. Food Microbiol 1998; 15: 207-14.

[22] Arroyo G, Sanz PD, Prestamo G. Effect of high pressure on the reduction of microbial populations in vegetables. J Appl Microbiol 1997; 82(6): 735-42.

[23] Ludwig H, Bieler C, Hallbauer K, Scigalla W. Inactivation of microorganisms by hydrostatic pressure. In: Balny C, Hayashi R, Heremans K, Masson P, Eds. High Pressure and Biotechnology. Paris: Colloque INSERM/John Libbey Eurotext Ltd., 1992; pp. 2532.

[24] Ludwig H, Gross P, Scigalla W, Sojka B. Pressure inactivation of microorganisms. High Press Res 1994; 12: 193-7.

[25] Mañas P, Mackey BM. Morphological and physiological changes induced by high hydrostatic pressure in exponential- and stationary-phase cells of Escherichia coli: relationship with cell death Appl Environ Microbiol 2004; 70(3): 1545-54.

[26] Gervilla R, Ferragut V, Guamis B. High pressure inactivation of microorganisms inoculated into ovine milk of different fat contents. J Dairy Sci 2000; 83(4): 674-82.

[27] Van Opstal I, Vanmuysen SC, Michiels CW. High sucrose concentration protects E. coli against high pressure inactivation but not against high pressure sensitization to the lactoperoxidase system. Int J Food Microbiol 2003; 88(1): 1-9.

[28] Hauben KJ, Bernaerts K, Michiels CW. Protective effect of calcium on inactivation of Escherichia coli by high hydrostatic pressure. J Appl Microbiol 1998; 85(4): 678-84.

[29] Sharma A, Scott JH, Cody GD, et al. Microbial activity at gigapascal pressures. Science 2002; 295(5559): 1514-6.

This is an open access article licensed under the terms of the Creative Commons Attribution Non-Commercial License (http: //creativecommons.org/licenses/by$\mathrm{nc} / 3.0 /$ ) which permits unrestricted, non-commercial use, distribution and reproduction in any medium, provided the work is properly cited. 